\title{
A Combined Energy Management Algorithm for Wind Turbine/ Battery Hybrid System
}

\author{
NECMI ALTIN ${ }^{1,3}$ and SÜLEYMAN EMRE EYIMAYA ${ }^{2,4}$ \\ 1.-Department of Electrical and Electronics Engineering, Faculty of Technology, Gazi \\ University, Teknikokullar, 06500 Ankara, Turkey. 2.-Electronics and Automation Department, \\ Ankara University Nallıhan Vocational School, Ankara, Turkey. 3.—e-mail: naltin@gazi.edu.tr. \\ 4.-—e-mail: seyimaya@ankara.edu.tr
}

From an energy management standpoint, natural phenomena such as solar irradiation and wind speed are uncontrolled variables, so the correlation between the energy generated by renewable energy sources and energy demand cannot always be predicted. For this reason, energy storage systems are used to provide more efficient renewable energy systems. In these systems, energy management systems are used to control the energy storage system and establish a balance between the generated power and the power demand. In addition, especially in wind turbines, rapidly varying wind speeds cause wind power fluctuations, which threaten the power system stability, especially at high power levels. Energy storage systems are also used to mitigate the power fluctuations and sustain the power system's stability. In these systems, another controller which controls the energy storage system power to mitigate power fluctuations is required. These two controllers are different from each other. In this study, a combined energy management algorithm is proposed which can perform both as an energy control system and a power fluctuation mitigation system. The proposed controller is tested with wind energy conversion system modeled in MATLAB/Simulink. Simulation results show that the proposed controller acts as an energy management system while, at the same time, mitigating power fluctuations.

Key words: Wind power, energy storage system, power fluctuation mitigation

\section{INTRODUCTION}

Increasing world power demand and increasing awareness of global warming and the green world concept, depletion of fossil fuels and the desire for energy independency have increased interest in renewable energy sources (RESs), and therefore the amount of research on RESs has increased exponentially in the last two decades. ${ }^{1-3}$ Among the RESs, wind energy is at the forefront with advantages such as being obtainable any season, day or night, and its competitive costs. Since wind is considered one of the most promising sources of

(Received November 24, 2017; accepted February 16, 2018; published online March 1, 2018) renewable energy, wind energy capacity has grown significantly in recent years, and now provides a large contribution to the current supply of electrical energy. Wind power provides a cost effective solution, especially for rural areas where building an integrated transmission system incurs a high cost. A micro-grid can be implemented for these kinds of areas. ideally, the wind or renewable energy sources should follow the load power demand in every condition to prevent fluctuations in voltage or frequency. Since the wind speed is a natural event and cannot be controlled, it presents a challenge to tracking the load demand. Therefore, micro-grids are designed as hybrid structures containing wind systems, photovoltaic (PV) systems, diesel generators and energy storage systems to provide continuous energy to loads. ${ }^{4-6}$ 
Suitable energy management systems and algorithms are required to manage hybrid systems in a coordinated manner. Several studies have been proposed for controlling PV, wind and diesel generator hybrid systems. ${ }^{78}$ In these systems, energy storage technologies are key components. Different energy storage technologies, such as pumped hydro storage systems, compressed air storage systems, batteries, flow batteries, hydrogen-based storage systems, superconducting magnetic energy storage systems, flywheels and supercapacitors can be used in both micro-grids and smart grids for various purposes, such as mitigating power fluctuations, improving the voltage and frequency stability and power quality of the system, spinning reserve and peak shaving, according to their properties. ${ }^{7,8}$

Several energy management schemes have been proposed for wind power systems. ${ }^{9-11}$ These methods usually focus on supplying loads continuously and matching the supply and demand. However, since the wind speed is variable, the power level obtained from the wind turbine is not consistent, varying with the wind speed, so power fluctuations can occurr. The power grid to which the wind turbine or the wind farm is connected then also suffers from these power fluctuations. Power fluctuations generated by a wind farm can cause some negative effects on stability, power quality and reliability of the power system. ${ }^{12}$ Some studies have been conducted on the negative effects of renewable energy systems on frequency and voltage fluctuations in power networks. ${ }^{13}$ Increasing integration of wind energy systems (and other RESs) into the power grid renders grid scale storage technologies more important, and has triggered many studies on integrated usage of energy storage systems with RESs. ${ }^{14}$ While energy storage systems can be used to provide continuous energy to loads, they can be also used to provide frequency regulation, voltage support or spinning reserve. Batteries, Flow batteries, Superconducting magnetic energy storage systems, flywheels and supercapacitors are commonly used in power fluctuation mitigation applications, providing fast response, high ramp power rates and long-life cycles. ${ }^{15}$

Battery energy storage systems (BESS systems) are static, compact, modular in nature, highly efficient, easy to install and have low maintenance cost and fast response. Therefore, they have attracted the attention of many researchers for grid scale energy storage applications, including power fluctuation mitigation of solar, wind or hybrid renewable energy systems, and for voltage and frequency support for smart grid systems. ${ }^{16,17}$ Although different BESS technologies have been investigated, the Lithium Ion (Li-on) batteries are the most common with their fast charge-discharge, fast response characteristics, and their high cycle life, power density and efficiency.

The control schemes required to determine reference power allowing the BESS to mitigate power fluctuations are different from energy management systems. The first-order low-pass filter (FLF) is the most common method for determining the reference power for the BESS. The time constant of the FLF is the major factor. Higher values of the time constant improve the fluctuation performance and smoother output power is obtained. However, this also increases the required BESS capacity. Similarly, a smaller time constant value decreases the BESS capacity requirement, but the fluctuation performance also decreases.

Therefore, some studies have been proposed to adjust the mitigation factor of the power fluctuations. Two-time-scale coordination, ${ }^{18}$ a dual-layer control strategy including a fluctuation mitigation control $^{12}$ and application of an automatic segmentation moving average ${ }^{19}$ are the methods proposed to provide required mitigation factors with reduced BESS capacity. Hybrid energy storage technologies, such as combining a BESS with a supercapacitor, are also proposed to decrease the capacity and increase the lifetime of the BESS. ${ }^{20}$

However, these studies are focused on mitigation of power fluctuations and do not contain energy support to the system. Similarly, the energy management methods focus only on the management of power sources and defining the reference power for each supply, and do not care about mitigation of the power fluctuations of RESs. Thus, two energy storage systems are required to cover two purposes. In this study, a combined control algorithm is proposed to manage these two actions for wind power generation systems. The Li-on based BESS is used as the energy storage system, and its reference power is defined to provide energy matching between supply and demand, to mitigate the power fluctuations and to improve power quality. The performance of the system is validated with simulation studies.

\section{FLUCTUATION MITIGATION REQUIREMENTS FOR WIND POWER GENERATION AND ENERGY STORAGE SYSTEMS}

Output power of a wind turbine varies with wind speed. Rapid changes in wind speed cause power fluctuations, which may threaten power system stability and power quality. Since the wind speed cannot be controlled, this cannot be prevented. These fluctuations have negative effects on power system stability, and have the potential to limit the amount of wind power that can be integrated to the power system. To address this concern, some precautions, such as protection and control algorithms, are presented. In some studies, pitch control is proposed to mitigate the power fluctuations of wind turbines. However, the speed of the pitch control action is limited, and therefore the required mitigation is not provided. ${ }^{21,22}$ 


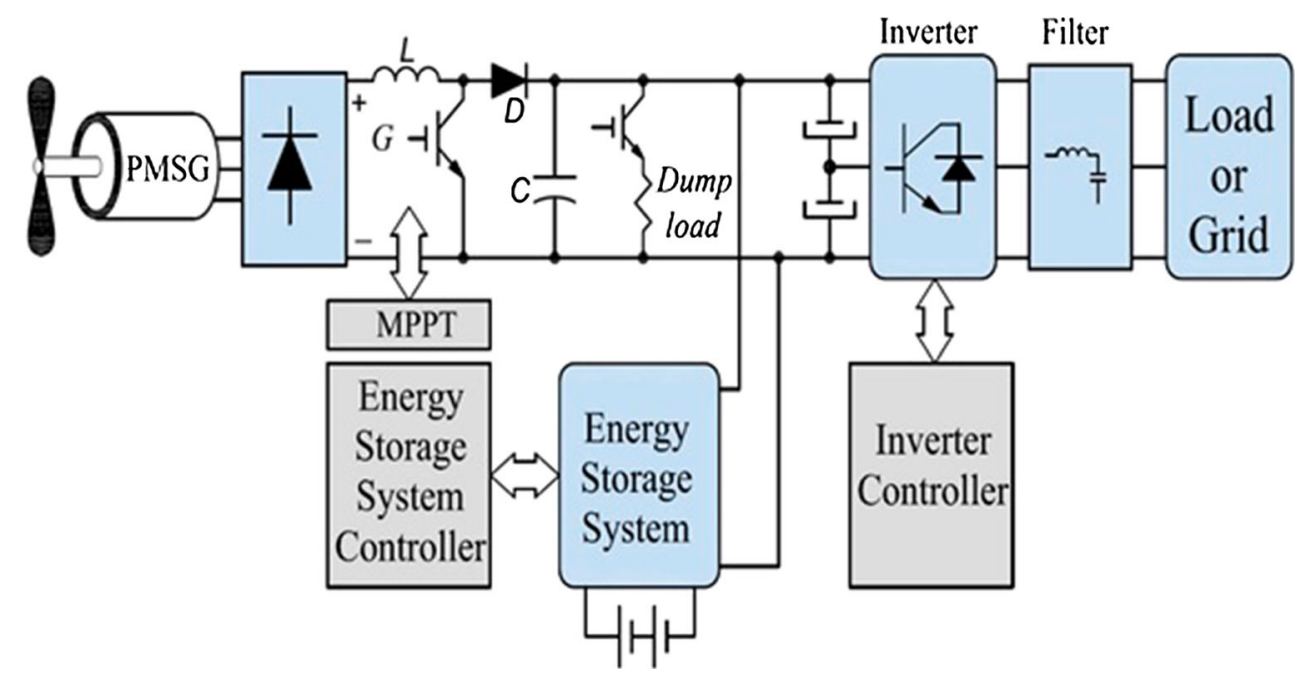

Fig. 1. Wind farm with energy storage system controller.

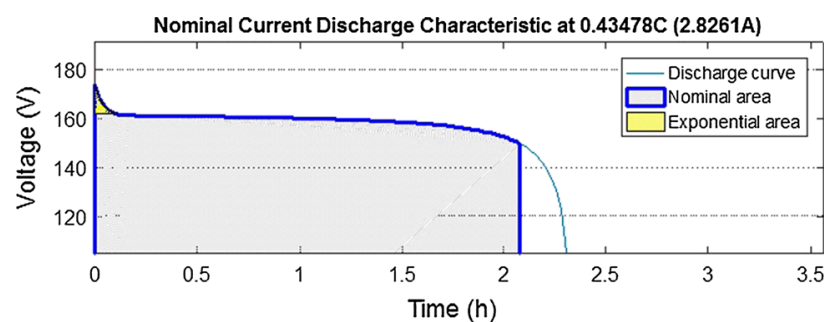

(a)

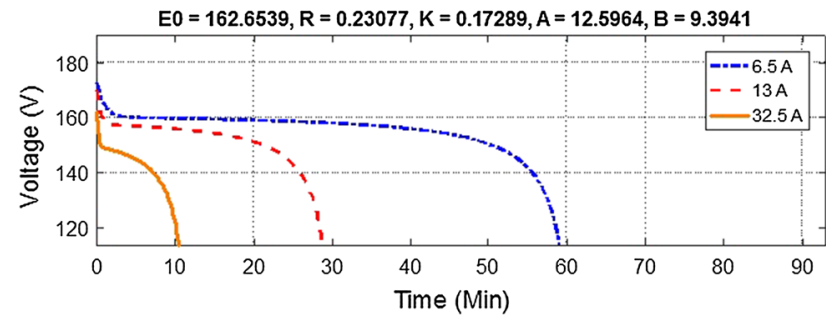

(b)

Fig. 2. The discharge characteristics of the BESS (a) at nominal current, and at (b) $6.5 \mathrm{~A}, 13 \mathrm{~A}$, and 32.5 A.

Energy storage systems are used in many power fluctuation mitigation applications. In these systems, a control algorithm determines a reference output power for the wind generator. If the wind power is higher than the determined output power, the excessive power is stored to the energy storage system. Otherwise, the required energy (difference between the reference power and the wind power) is supplied by the energy storage system, and injected to the power system or to the load. Since the variations in wind speed may be rapid, the frequency of the resulting fluctuations could be high. Therefore, the energy storage technology used in these applications should have fast response, fast charge-discharge characteristics, high efficiency and high cycle life characteristics. The BESS, flow batteries, superconducting magnetic energy systems, flywheel energy systems, and supercapacitors can be used in these applications. ${ }^{23-26}$ Thanks to recent improvements, the BESS seems to be the most suitable technology for these applications. Besides the other applications, such as uninterruptible power supplies, electrical vehicles and portable electronic devices, the BESS systems are also used in grid scale energy storage applications for different purposes, such as voltage support, frequency support, spinning reserve, peak shaving, etc.

The combination of a proper control algorithm with a suitable storage technology (with the new developments in energy storage technologies) offers an opportunity to increase the usage and the integration of wind energy conversion systems. ${ }^{27}$ Various effective BESS-containing methods have been proposed to mitigate power fluctuations in renewable energy generation systems, ${ }^{28,29}$ but a system that completely eliminates the ripple for grid-connected wind and PV farms has not been formally described. For renewable energy sources, smoothing control through power fluctuation rate limits is rarely discussed. Small-scale BESS systems are formulated to mitigate power fluctuations, but power distribution among several BESS systems is not considered in larger scale systems. ${ }^{30,31}$ Therefore, it is necessary to design an appropriate and effective control strategy for a large-scale BESS as an urgent requirement.

\section{PROPOSED CONTROL SYSTEM}

The block diagram of the overall system is given in Fig. 1. The proposed system consists of a permanent magnet synchronous generator (PMSG), a rectifier, a maximum power point tracking (MPPT) 
boost converter and an MPPT algorithm, an inverter, a Li-on based BESS, a bidirectional direct current-direct current (DC-DC) converter, a dump load, the load (or the grid) and the control system.

\section{The Wind Energy Conversion System Model}

The model of the wind energy conversion system consists of a three-phase silent pole $8.5 \mathrm{~kW}$ PMSG, a wind turbine and a pitch angle control system. The PMSG generates three-phase alternating current. However, its voltage and frequency values depend on the wind speed. Therefore, the output voltage of the PMSG is rectified to provide constant frequency, constant voltage alternating current (AC) power. Next to the rectifier circuit, the MPPT boost converter is employed to provide maximum energy conversion efficiency. The MPPT algorithm generates a torque reference by using the wind speed variable. Then current reference is obtained by using the generated torque reference, the rectified direct current (DC) voltage and the wind speed. A hysteresis controller generates the switching signal to the boost converter by comparing this current reference and the actual current value.

The MPPT boost converter tracks the maximum power point of the wind energy conversion system and generates the common DC bus voltage for the system. The dump load and BESS-based energy storage system (through the bidirectional converter) are also connected to this common DC bus. The dump load prevents damage to the wind turbine and high voltages at the DC bus. The DC bus is set to a specific value, and if the state of charge (SOC) of the BESS is higher than $80 \%$, the dump load is activated. Instead of directly connecting it to the DC bus, a controller and a pulse width modulation (PWM) generation unit are employed, and highprecision control is obtained.

The BESS is connected to the common DC bus via a bidirectional DC-DC converter to stabilize and mitigate the power fluctuations occurring in the wind energy conversion system's output power. The $150 \mathrm{~V}, 6.5 \mathrm{Ah}$ Li-on battery is modeled and used. The charge-discharge characteristics of the BESS is depicted in Fig. 2.

In this study, the conventional energy management algorithm is modified to provide the ability to mitigate power fluctuations. A conventional energy management system provides a balance between the generated power and the demand. Therefore, it can be described with the common DC bus voltage

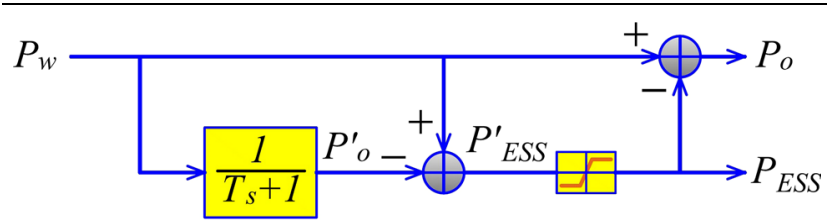

Fig. 3. FLF-based control of energy storage systems. control action. If the wind energy conversion system's output power is higher than the load power (or higher than the reference power value injected to the grid), the DC bus voltage increases. Similarly, if the output power of the wind energy conversion system is lower than the load demand power, the DC bus voltage decreases. This variation shows the imbalance between generation and demand. Based on this variation, a simple voltage controller can be used as an energy management system. If the common DC voltage is higher than the determined reference voltage level, this shows that the generated power is higher than the demand power. In this case, the controller generates a negative power reference for the BESS, and the BESS is charged. Contrarily, when the common DC bus voltage is lower than the reference voltage level, the controller generates a positive power reference for the BESS, and the BESS is discharged. This is given in Eqs. 1 and 2 :

$$
\begin{gathered}
e_{v}(t)=V_{\text {DC_ref }}-v_{\mathrm{dc}}(t) \\
i_{\text {bat } \_l}(t)^{*}=K_{\mathrm{p}}(e(t))+K_{\mathrm{i}} \int(e(t)) \mathrm{d} t,
\end{gathered}
$$

where $e_{v}(t)$ is the difference between the reference common DC bus voltage $\left(V_{\text {DC_ref }}\right)$ and the actual common DC bus voltage $\left(v_{\mathrm{dc}}(t)\right), i_{\text {bat_e }}(t)^{*}$ is the conventional energy management component of the battery reference current, and $K_{\mathrm{p}}$ and $K_{\mathrm{i}}$ are the proportional and integral gains of the proportionalintegral (PI) controller, respectively.

If the $i_{\text {bat } e}(t)^{*}$ is used as the battery reference current, only the energy balance between the wind energy conversion system and the load (or the grid) is provided. In this condition, the system suffers from the power fluctuations generated by the wind speed variations, and stability of the system weakens. Therefore, in this study, this energy management system is modified by adding a power fluctuation mitigation stage.

An FLF is commonly used in power fluctuation mitigation applications. The basic principle of an FLF-based power fluctuation mitigation application is given in Fig. 3. As the figure shows, the wind power is applied to the FLF, and the difference between the wind power and the FLF output determines the energy storage system power reference. The FLF is described by Eq. 3:

$$
\mathrm{FLF}(s)=\frac{1}{1+\mathrm{Ts}_{\mathrm{s}}},
$$

where $T$ is the time constant of the FLF, exerting a direct effect on both the power fluctuation mitigation performance of the system and the required BESS capacity. The reference power for the BESS is obtained as follows:

$$
P_{\mathrm{ESS}}^{\prime}=P_{\mathrm{W}}-\frac{1}{1+\mathrm{Ts}} P_{\mathrm{W}}=\frac{\mathrm{Ts}}{1+\mathrm{Ts}} P_{\mathrm{W}}
$$




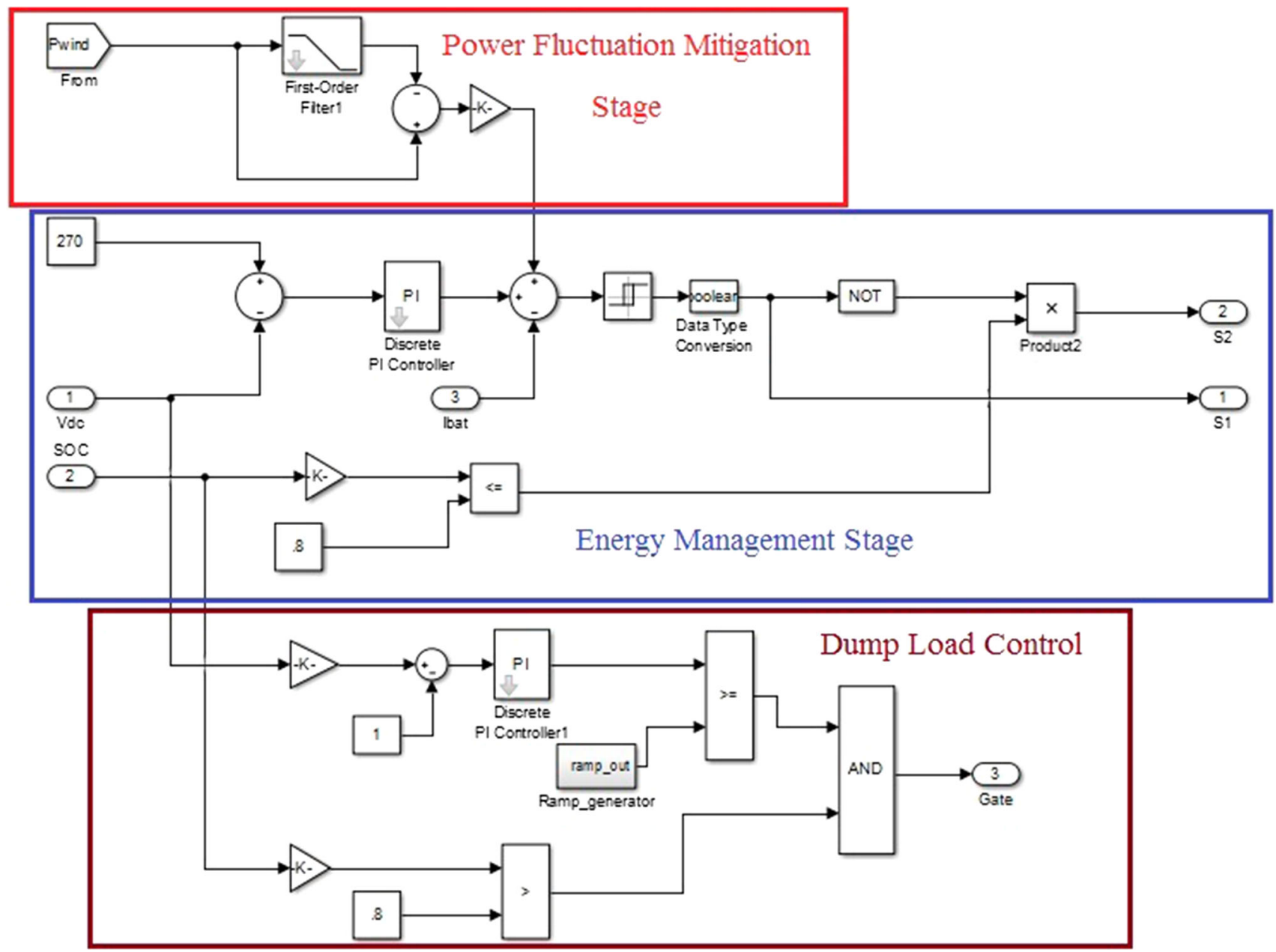

Fig. 4. The proposed combined energy management algorithm.

where $P_{\text {ESS }}^{\prime}$ is the reference power of the BESS and $P_{\mathrm{W}}$ is the power of the wind energy conversion system. By using these equations and the reference voltage of the common DC bus, the reference current component $\left(i_{\text {bat } f}(t)^{*}\right)$ of the BESS related to power fluctuation mitigation can be obtained as:

$$
i_{\text {bat_f }}(t)^{*}=\frac{1}{V_{\text {DC_ref }}} \frac{\mathrm{Ts}}{1+\mathrm{Ts}_{\mathrm{s}}} P_{\mathrm{W}}
$$

Finally, the reference power of the $\operatorname{BESS}\left(i_{\text {bat }}(t)^{*}\right)$ is obtained as:

$$
i_{\text {bat }}(t)^{*}=i_{\text {bat } \_e}(t)^{*}+i_{\text {bat } \_f}(t)^{*} .
$$

The actual current of the BESS is controlled by the hysteresis current controller, which has superior advantages such as fast response and easy implementation. The proposed energy management algorithm, including the energy management stage, the power fluctuation mitigation stage and the dump load stage, is depicted in Fig. 4.

The conventional three-phase voltage source inverter converts DC power, provided by both the wind energy conversion system and the BESS, to
$\mathrm{AC}$ and supplies the load (or grid). Insulated gate bipolar transistors (IGBTs) are used as power switches in the inverter model.

\section{SIMULATION RESULTS}

The wind energy conversion system, the rectifier and inverter circuits, the MPPT boost converter, the BESS and the bidirectional DC-DC converter were modeled and simulated in MATLAB/Simulink. Both wind speed and load power were changed to test the performance of the proposed energy management algorithm. In this case, variations of the active and the reactive power of the load, the BESS power and the wind power are shown in Fig. 5. As can be easily seen from the figure, the wind power has a significant number of fluctuations, which may have a negative effect on system stability.

We can see that according to the wind speed and the load demand, the wind power can be lower or higher than the load power demand. However, thanks to the BESS and the energy management algorithm, the load power is kept constant at its desired value. In addition, it can be seen that the 


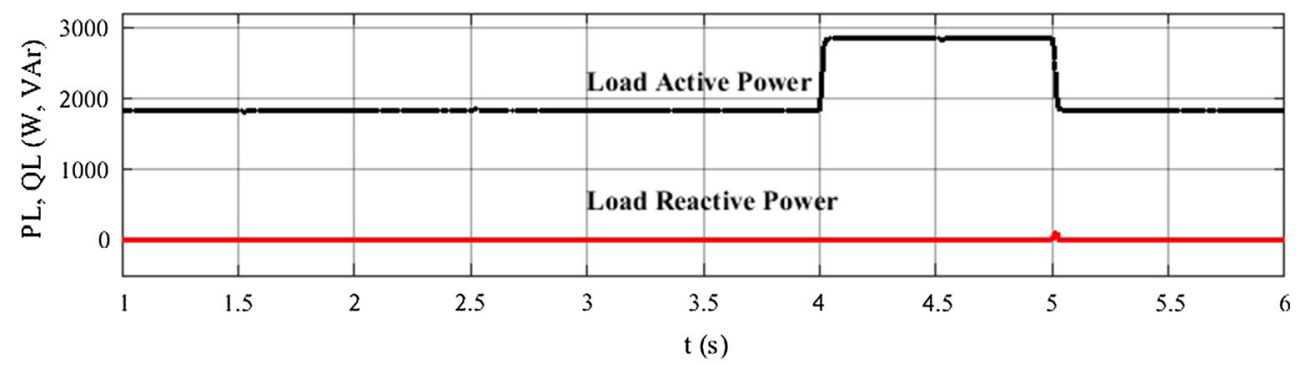

(a)

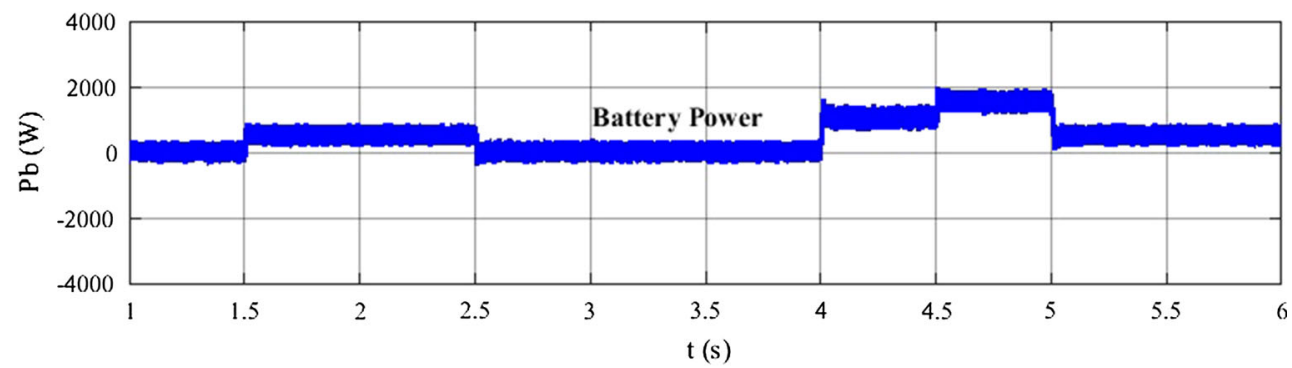

(b)

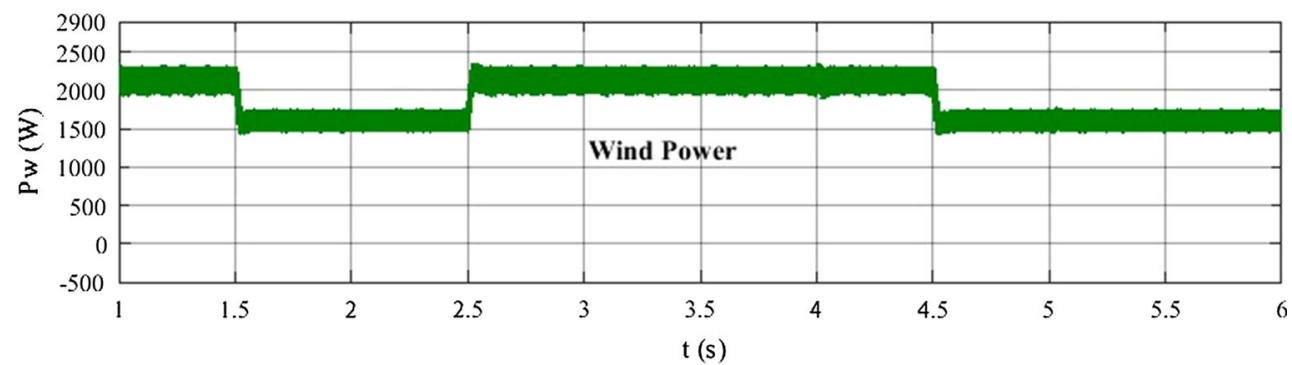

(c)

Fig. 5. Variations of power: (a) the load active and reactive power, (b) the battery power, and (c) the wind power.

proposed algorithm provides energy balance between the power of the wind energy conversion system, which depends on the wind speed, and the load power demand, and it mitigates the power fluctuations. Thus, load power quality of the off-grid systems, especially, is improved. In addition, when sudden changes on both the wind speed and the load power demand occur, the proposed system provides fast transient response and prevents power oscillations.

\section{CONCLUSIONS}

In this study, a combined energy management algorithm is proposed for a wind energy conversion system, supported by a BESS, to provide energy matching between generation and demand. The proposed energy management system combines energy management and power fluctuation mitigation actions, thus the requirement of a separate energy storage system for each purpose is removed. The proposed system was tested for variable wind speed and load power demand conditions. Results showed that the proposed system can provide energy balance between the generated power, which varies with wind speed, and load demand, and it mitigates power fluctuations. Thus, the proposed combined algorithm improves system stability, reliability and power quality, while providing energy matching. In addition, we demonstrated that the proposed system has fast transient response and provides stable operation for any condition. Since the proposed system performs two actions and removes the additional energy storage system requirement, it also improves system cost and efficiency.

\section{REFERENCES}

1. J.E.S. de Haan, and W.L. Kling, in Innovative Smart Grid Technologies Conference Europe, IEEE PES (2010) pp. 1-8.

2. S.M. Hosseinpour-Mashkani, M. Maddahfar, and A. Sobhani-Nasab, S. Afr. J. Chem. 70, 44 (2017).

3. A. Sobhani-Nasab, S.M. Hosseinpour-Mashkani, M. Salavati-Niasari, H. Taqriri, S. Bagheri, and K. Saberyan, J. Mater. Sci.: Mater. Electron. 26, 5735 (2015).

4. H. Babazadeh, W. Gao, Z. Wu, and Y. Li, in North American Power Symposium (NAPS) (2013) pp. 1-5.

5. D.S. Koussa, M. Koussa, A. Rennane, S. Hadji, A. Boufertella, A. Balehouane, and S. Bellarbi, Energy 130, 38 (2017). 
6. H. Fathabadi, Energy 140, 454 (2017).

7. P.F. Ribeiro, B.K.J. Mariesa, L. Crow, A. Arsoy, and Y. Liu, Proc. IEEE 89, 1744 (2001).

8. N Altin, in International Smart Grid Workshop and Certificate Program (ISGWCP) (2016), pp. 48-54.

9. S.M. Mousavi, S.H. Fathi, and G. H. Riahy, in International Conference on Clean Electrical Power (2009), pp. 630-633.

10. M. Dali, J. Belhadj, and X. Roboam, Energy 35, 2587 (2010).

11. P. García, J.P. Torreglosa, L.M. Fernández, and F. Jurado, Int. J. Hydrog. Energy 38, 14146 (2013).

12. Q. Jiang, Y. Gong, and H. Wang, IEEE Trans. Power Syst. 28,3263 (2013).

13. T. Shinji, T. Sekine, A. Akisawa, T. Kashiwagi, G. Fujita, and M. Matsubara, Electr. Eng. Jpn 163, 22 (2008).

14. S. Vazquez, S.M. Lukic, E. Galvan, L.G. Franquelo, and J.M. Carrasco, IEEE Trans. Ind. Electron. 57, 3881 (2010).

15. J.M. Carrasco, L.G. Franquelo, J.T. Bialasiewicz, E. Galván, R.C. Portillo Guisado, M.M. Prats, J.I. Leónand, and N. Moreno-Alfonso, IEEE Trans. Ind. Electron. 53, 1002 (2006).

16. Q. Jiang, Y. Gong, and H. Wang, IEEE Trans. Power Syst. 28,3263 (2013).

17. K.J.P. Macken, T.C. Green, and R.J.M. Belmans, in IEEE International Conference on Harmonics and Quality of Power (2002), pp, 776-781.

18. Q. Jiang and H. Wang, IEEE Trans. Energy Convers. 28, 52 (2013).
19. W. Wang, C. Mao, J. Lu, and D. Wang, Energies 6, 3392 (2013).

20. D. Buddika, W. Abeywardana, B. Hredzak, and V.G. Agelidis, IEEE Trans. Power Electron. 32, 667 (2017).

21. H.C. Sung, J.B. Park, and Y.H. Joo, Int. J. Control Autom. Syst. 9, 1103 (2011).

22. T. Yamazaki, R. Takahashi. T. Murata, and J. Tamura, in 18th International Conference on Electrical Machines (2008), pp. 1-6.

23. F. Zhou, G. Joos, C. Abbey, L. Jiao, and B. T. Ooi, in $E E E$ Power and Energy Society General Meeting (2004), pp. 2025-2030.

24. R. Cardenas, R. Pena, G. Asher, and J. Clare, IEEE Trans. Energy Convers. 19, 206 (2004).

25. S.M. Muyeen, R. Takahashi, T. Murata, and J. Tamura, IEEE Trans. Energy Convers. 24, 740 (2009).

26. T. Kinjo, T. Senjyu, N. Urasaki, and H. Fujita, IEEE Trans. Energy Convers. 21, 221 (2006).

27. T. Hennessy and M. Kuntz, in IEEE Power and Energy Society General Meeting (2005), pp. 1952-1954.

28. M.E. Baran, S. Teleke, L. Anderson, A.Q. Huang, S. Bhattacharya, and S. Atcitty, in IEEE Power and Energy Society General Meeting-Conversion and Delivery of Electrical Energy in the 21st Century (2008), pp. 1-6.

29. C. Abbey, K. Strunz, and G. Joós, IEEE Trans. Energy Convers. 24, 539 (2009).

30. X. Li, Y. Li, X. Han, and D. Hui, Energy Proced. 12, 994 (2011).

31. X. Li, IET Renew. Power Generat. 6, 340 (2012). 